\title{
Aphids on Landscape Plants 1
}

\section{E. A. Buss ${ }^{2}$}

Aphids or "plant lice" may infest almost any plant. They are more commonly found on camellia, crape-myrtle, gardenia, hibiscus, ixora, oleander, palm, rose, as well as nearly all annual plants. Aphids have piercing-sucking mouthparts and cause damage by sucking the plant juices. However, their ability to transmit plant viruses may be more harmful than any direct feeding damage.

Aphids (Figure 1) are soft bodied pear-shaped insects generally less than $1 / 8$ inch long and usually green in color but many are black, brown, pink, yellow, blue, or white. Most aphids are wingless but when colonies become overcrowded or the host plant becomes undesirable, winged forms are produced which establish new colonies. Aphids have two short cornicles or tubes at the end of their bodies. These insects are commonly found on the stems or undersides of young leaves in small colonies.

Most aphids feed on the new flush of growth in the early spring, but they may be found throughout the year. Their feeding makes the leaves curl or crinkle and flower buds may become hardened, causing the flowers to be distorted.

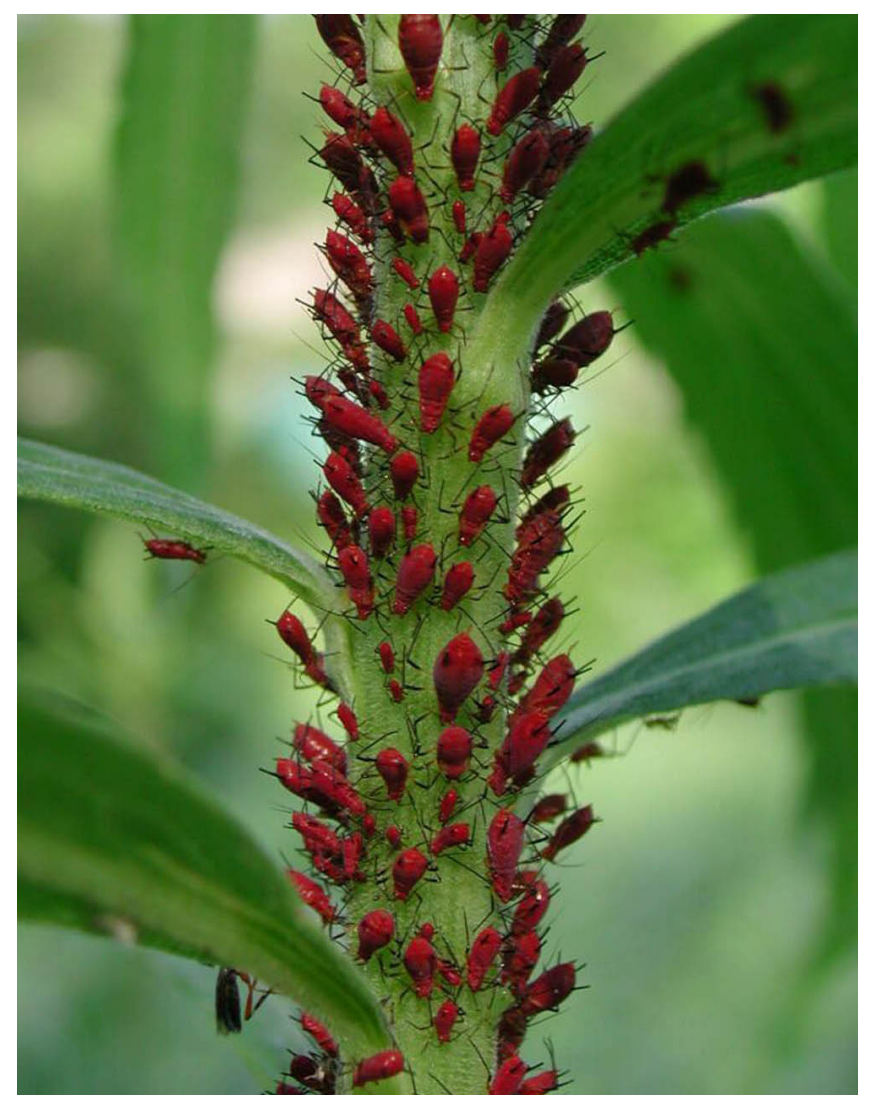

Figure 1. Aphids feeding on plant stem. Credits: Eileen Buss, University of Florida

1. This document is ENY-320 (MG002), one of a series of the Department of Entomology and Nematology, Florida Cooperative Extension Service, Institute of Food and Agricultural Sciences, University of Florida. Date first printed, October 1993. Revised: June 2006. Please visit the EDIS Website at http://edis.ifas.ufl.edu.

2. E. A. Buss, assistant professor, Department of Entomology and Nematology, Cooperative Extension Service, Institute of Food and Agricultural Sciences, University of Florida, Gainesville, 32611. other services only to individuals and institutions that function with non-discrimination with respect to race, creed, color, religion, age, disability, sex, sexual orientation, marital status, national origin, political opinions or affiliations. U.S. Department of Agriculture, Cooperative Extension Service, University of Florida, IFAS, Florida A. \& M. University Cooperative Extension Program, and Boards of County Commissioners Cooperating. Larry Arrington, Dean 
Aphids are unlike most insects in two ways: almost all are females that reproduce without mating, and most give birth to living young instead of laying eggs. Aphids have the ability to reproduce rapidly and there are many generations per year. Each female aphid produces 50 to 100 daughters during her life span and each daughter can reproduce within 6 to 8 days.

Aphids as well as soft scales, mealybugs, and whiteflies excrete large amounts of honeydew which provides an excellent medium for the growth of a black fungus called "sooty mold." Besides being unattractive, sooty mold may interfere with photosynthesis and retard plant growth. Sooty mold usually weathers away following control of an insect infestation. Ants feed on the honeydew and when ants are observed, plants should be examined closely for these sucking pests.

\section{Beneficial Insects}

Some examples of aphid predators are lady beetles, praying mantids, assassin bugs, ambush bugs, and aphid lions. Spiders also prey on numerous insect pests. Aphids that have a small hole in a bloated-looking body were parasitized by tiny wasps (Figure 2). If predators are present or the pests show signs of parasitism, every effort should be made to preserve the beneficial insects. Delay applying a pesticide until damage appears, and provide the beneficials an opportunity to control the pest populations.

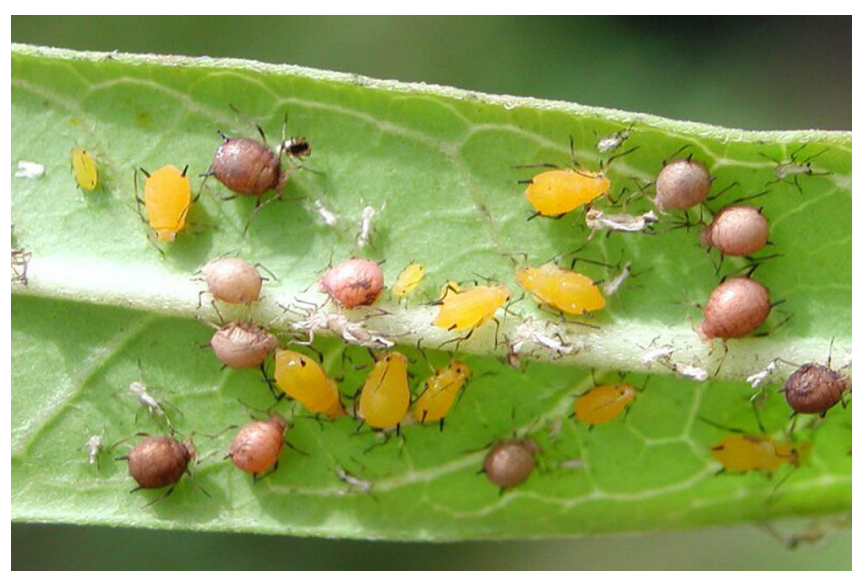

Figure 2. Healthy (yellow) and parasitized (brown/swollen) oleander aphids. Credits: Eileen Buss, University of Florida

\section{Inspecting Plants}

Examine your plants weekly during the spring, summer, and fall. Look at the undersides of a few leaves on each plant and observe the stems for aphids, especially the new growth. The use of a 10 to 15 power hand lens or magnifying glass aids in detection and identification. Learn to determine when aphids are present in damaging numbers and to evaluate the potential of the predator or parasite population. To aid in locating aphids, a sheet of white paper or cloth may be held beneath the leaves and the foliage struck sharply. The insects will fall onto the paper and can be more easily observed and identified than on the green foliage.

\section{Non-Insecticidal Control}

Many homeowners can remove aphids and keep populations below damaging levels by spraying their landscape plants with a forceful stream of water. Use a garden hose with an adjustable nozzle and spray undersides of leaves and stems when the aphids appear.

Soaps are available that are formulated for controlling insects and related pests. If one of the commercial soaps is unavailable, 3 tablespoons of dishwashing liquid (do not use those containing a degreaser or an automatic dishwashing soap or detergent) per gallon of water may be applied as a foliar spray to woody plants. Use 2 tablespoons for bedding, foliage and flowering plants. Repeat at weekly intervals as needed. Soap is effective in controlling aphids, safe for people and the environment.

\section{Insecticidal Control}

Usually aphids are not difficult to control with insecticides. But, plants may become re-infested from adjacent areas throughout the year. For control, apply one of the suggested insecticides (see Tables 1 and 2) if aphids are beginning to damage the plants. Spray the plants to the point of run-off. Be especially careful to cover the undersides of the leaves and all parts of the twigs thoroughly. Continue to inspect the plants periodically especially new flushes of growth and apply an insecticide if plants become re-infested. 
Table 1. Insecticides labeled for non-commercial (homeowner) use against aphids in Florida.

\begin{tabular}{||l|l|l||}
\hline \multicolumn{1}{|c|}{ Active Ingredient } & \multicolumn{1}{|c||}{ Trade Name } & \multicolumn{1}{|c||}{ Chemical Class } \\
\hline Bifenthrin & Ortho Bug-B-Gon Max Lawn \& Garden Insect Killer & Pyrethroid \\
\hline Carbaryl & Sevin & Carbamate \\
\hline Cyfluthrin & $\begin{array}{l}\text { Bayer Advanced Power Force Multi-insect Killer } \\
\text { Bayer Advanced Rose \& Flower Insect Killer } \\
\text { Schultz Lawn \& Garden Insect Killer }\end{array}$ & Pyrethroid \\
\hline Deltamethrin & Green Light House \& Yard & Pyrethroid \\
\hline Imidacloprid & $\begin{array}{l}\text { Bayer Advanced Lawn Complete Insect Killer } \\
\text { Bayer Advanced Tree \& Shrub Insect Control }\end{array}$ & Pyrethroid \\
\hline Lambda-cyhalothrin & Spectracide Triazicide Once \& Done Insect Killer & Organophosphate \\
\hline Malathion & $\begin{array}{l}\text { Green Light Malathion } \\
\text { Ortho Malathion Plus Insect Spray }\end{array}$ & Botanical \\
\hline Neem Oil & $\begin{array}{l}\text { Bonide Safer BioNeem } \\
\text { Green Light Neem } \\
\text { Green Light Rose Defense } \\
\text { Southern Ag Triple Action Neem Oil }\end{array}$ & Biorational \\
\hline Paraffinic Oil & $\begin{array}{l}\text { Bonide All Seasons Horticultural and Dormant Spray Oil } \\
\text { SunSpray Horticultural Oil }\end{array}$ & Pyrethroid \\
\hline Permethrin & $\begin{array}{l}\text { Bonide Eight Liquid } \\
\text { Green Light Conquest Home Pest Control } \\
\text { Hi-Yield Indoor/Outdoor Broad Use Insecticide } \\
\text { Ortho Bug-B-Gon Max Garden Insect Dust }\end{array}$ & Biorational \\
\hline Potassium Salts & Safer's Insecticidal Soap & Botanical \\
\hline Pyrethrins & $\begin{array}{l}\text { Bonide Yard \& Garden Insect Killer } \\
\text { Spectracide Bug Stop Insect Killer } \\
\text { Spectracide Rose \& Flower Insect Spray }\end{array}$ & \\
\hline \hline
\end{tabular}


Table 2. Insecticides labeled for professional use applicators to control aphids.

\begin{tabular}{||l|l|l|l||}
\hline \hline \multicolumn{1}{|c|}{ Brand Name } & \multicolumn{1}{c|}{ Active Ingredient } & \multicolumn{1}{c||}{ Chemical Class } & \multicolumn{1}{c||}{ Signal Word } \\
\hline Aria & Flonicamid & Neonicotinoid & Caution \\
\hline Astro & Permethrin & Pyrethroid & Caution \\
\hline Avid & Abamectin & Macrocyclic Lactone & Warning \\
\hline Azatin & Azadirachtin & Botanical & Caution \\
\hline DeltaGard T\&O & Deltamethrin & Pyrethroid & Caution \\
\hline Endeavor & Pymetrozine & Triazine & Caution \\
\hline Flagship & Thiamethoxam & Neonicotinoid & Caution \\
\hline Horticultural Oils & Paraffinic oil & Oil & Caution \\
\hline Insecticidal Soaps & Potassium salts of fatty acids & Soap & Caution \\
\hline Malathion & Malathion & Organophosphate & Caution \\
\hline Merit & Imidacloprid & Neonicotinoid & Caution \\
\hline Safari & Tebufenozide & Neonicotinoid & Caution \\
\hline Scimitar & Lambda-cyhalothrin & Pyrethroid & Caution \\
\hline Sevin & Carbaryl & Carbamate & Caution \\
\hline Talstar & Bifenthrin & Pyrethroid & Caution \\
\hline Tempo & Cyfluthrin & Pyrethroid & Caution \\
\hline \hline
\end{tabular}

